Sorption enhanced methanation for substitute natural gas production: Experimental results and thermodynamic considerations

S. Walspurger G.D. Elzinga J.W. Dijkstra M. Saric W.G. Haije 


\title{
Sorption enhanced methanation for substitute natural gas production: Experimental results and thermodynamic considerations
}

\author{
Stéphane Walspurger*, Gerard D. Elzinga, Jan Wilco Dijkstra, Marija Sarić, Wim G. Haije \\ ECN, Energy Research Centre of The Netherlands, P.O. Box 1, 1755 ZG Petten, The Netherlands
}

\section{H I G H L I G H T S}

- High grade SNG production at methanation pressure below 10 bar. - Sorption enhanced methanation process saves up to $40 \%$ compression duty.

- Commercial Nickel based catalyst and zeolite $4 \mathrm{~A}$ yield $100 \% \mathrm{CH}_{4}$ between 250 and $350{ }^{\circ} \mathrm{C}$.

\section{A R T I C L E I N F O}

\section{Article history:}

Received 13 September 2013

Received in revised form 16 December 2013

Accepted 18 December 2013

Available online 28 December 2013

\section{Keywords:}

Methanation

Sorption enhanced reaction process

Adsorption

Substitute natural gas

Dehydration

Gas purity

\section{G R A P H I C A L A B S T R A C T}

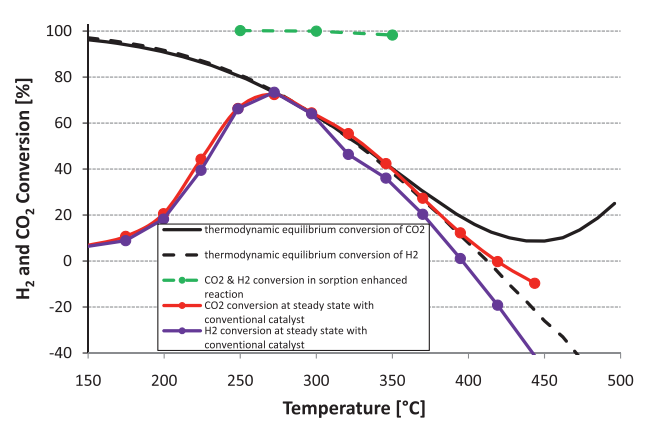

\begin{abstract}
A B S T R A C T
The Sabatier process may become a ubiquitous process for the production of renewable substitute natural gas from biomass or from any $\mathrm{CO}_{2}$ source coupled with renewable hydrogen. While a conventional Sabatier process typically requires cascade reactors and high operational pressure, i.e. $40-60$ bars at least, to yield an SNG product matching the specification for injection in the natural gas infrastructure, the sorption enhanced Sabatier reaction has the potential of producing high grade methane product at operational pressures below 10 bar. The energy duty for compression work may then decrease from $10 \%$ to $6 \%$ of the total process energy balance, in the case where reactants are supplied at atmospheric pressure. The sorption enhanced methanation was demonstrated at atmospheric pressure with commercial Nickel based catalyst and zeolite $4 \mathrm{~A}$ adsorbent between 250 and $350{ }^{\circ} \mathrm{C}$ reaching close to $100 \%$ conversion.
\end{abstract}

(c) 2014 Elsevier B.V. All rights reserved.

\section{Introduction}

Nowadays the economical and societal development relies heavily on fossil fuels in both developed and developing countries. A major drawback of this development pattern is the accumulation of an enormous quantity (400 ppm) of the greenhouse gas $\mathrm{CO}_{2}$ in the atmosphere that has a significant role in climate change. Furthermore the amount of affordable fossil fuels is finite and conventional oil and gas resources are rapidly being depleted. However with the increasing penetration of solar and wind technologies

\footnotetext{
* Corresponding author. Tel.: +31 (0)224564853; fax: +31 (0)224568487.

E-mail address: walspurger@ecn.nl (S. Walspurger).
}

for electricity generation, the production of renewable fuels becomes an attractive option to recycle $\mathrm{CO}_{2}$ while decreasing the global $\mathrm{CO}_{2}$ emissions and becomes an economically viable alternative to ever more costly unconventional fossil fuels [1-3]. Methanol, Hydrogen, Methane, Formic Acid, Ammonia may all fulfil the criteria of renewable fuel. While methanol has many advantages concerning transport and storage as a liquid fuel and the possibility of direct conversion to base chemicals via the methanol to olefin route [4], hydrogen which is the carbon neutral fuel par excellence cannot be conveniently and cheaply transported and stored for further use. Methane is an outstanding renewable fuel, being a hydrogen-rich energy carrier with a relatively high energy density compared to hydrogen. Remarkably, renewable methane 
generated by biomass fermentation, also called biogas or biomethane, has been introduced in many countries as a primary energy resource for the generation of heat and power or for direct injection in gas grids for the distribution of energy to industrial or private end users. Furthermore the use of renewable methane benefits from a relatively large public acceptance and benefits from the transmission, distribution and storage infrastructure that has been continuously improved for the use of natural gas for many decades [5]. Of particular interest, natural gas storage is currently used for the seasonal and strategic storage of primary energy and has sufficient discharge time and capacity to provide a reliable secured renewable fuel supply. With the soaring production of gas from tight gas and shale gas reservoirs, and the development of liquified natural gas (LNG) large facilities, the globalized gas transport infrastructure will be undoubtedly a key platform in the transition towards the use of a fully sustainable energy mix [6].

The conversion of renewable power to renewable methane enables connecting the existing power grid and natural gas grid thereby allowing for adjusted storage of significant amounts of power and providing $\mathrm{CO}_{2}$-neutral fuels using the natural gas grid and associated infrastructure as a storage facility [7]. For instance using the excess renewable electricity available from the large capacity renewable technologies for $\mathrm{H}_{2}$ production via the electrolysis of water and subsequent reduction of captured $\mathrm{CO}_{2}$ in a methanation or Sabatier process offers a method of converting the excess electricity into renewable methane.

In this perspective, the catalytic conversion of $\mathrm{CO}_{2}$ and $\mathrm{H}_{2}$ to methane that has been discovered in the early 20th century by Sabatier and Senderens [8], is of great interest. The formation of methane is a very exothermic process favoured at low temperature and high pressure by the following thermodynamic equilibrium:

\section{$\mathrm{CO}_{2}+4 \mathrm{H}_{2} \Longleftrightarrow \mathrm{CH}_{4}+2 \mathrm{H}_{2} \mathrm{O} \quad \Delta \mathrm{H}_{298}=-165 \mathrm{~kJ} / \mathrm{mol}$}

Commercial catalytic materials usually operate preferably between 250 and $450{ }^{\circ} \mathrm{C}$, up to $600^{\circ} \mathrm{C}$ for the most robust generation, and were developed for the substitute natural gas (SNG) synthesis from heavy feedstock, coal or biomass [9]. The conventional process uses a cascade of adiabatic reactors with intermediate cooling steps and recycles [10] to reach sufficiently high methane purity in the SNG product in order to allow for injection in the natural gas grid that has tight compositional specifications. In the methanation process, it is important to recover and use the heat released by the methanation reaction smartly since it represents about $20 \%$ of the energy provided to the system.

In this work, the sorption enhanced methanation reaction concept based on the Le Chatelier principle and already applied in other thermodynamic equilibrium based reactions [11-16] is studied both to improve the use of excess heat provided by the methanation reaction and to reach high SNG grade, possibly at lower operational pressure. Accordingly, the steam generated by the methanation reaction is removed from the gas phase in the catalytic bed by adding a sorbent material to the catalyst or more conveniently by designing a catalyst with adsorbent functionality [17]. This dehydration of the SNG product is thus carried out simultaneously with the methanation reaction in a regenerative process that uses heat to desorb the water from the sorbent material. The strategy for the regeneration of the sorbent may be designed based on the materials properties (steam capacity, adsorption energy) and consists of temperature swing and/or pressure swing with or without purge gas, in circulating bed or fixed bed reactors.

In the first part of this contribution the detailed discussion of the analysis of the thermodynamics shows to what extent higher methane quality may be reached by implementing the sorption enhanced process, as well as the limits of the process. In the second part of this paper experimental work provides a proof of concept of the sorption enhanced methanation process that may be used as a ubiquitous SNG upgrading process for the production of renewable methane and SNG from biomass. While the thorough study of the process design remains out of the scope of the present article, the plausible regenerative conditions are discussed in the last section.

\section{Materials and methods}

The thermodynamic modelling of the methanation process by conversion of $\mathrm{H}_{2}$ and $\mathrm{CO}_{2}$ was developed in the flow-sheeting tool ASPEN Plus to identify the feed characteristics and the target performance of the methanation reactor(s). A basis of design study gave the starting points of modelling and the battery limit conditions. The $\mathrm{CO}_{2}$ stream considered for the simulation had a purity of $100 \%$ and was available at 1.6 bar and $40^{\circ} \mathrm{C}$, which are typically the specifications found in $\mathrm{CO}_{2}$ captured in industrial process using amine absorption, that is further used in food industry for example. The hydrogen produced by an electrolysis process had a purity of $100 \%$ and was delivered at 1 bar and $40^{\circ} \mathrm{C}$ to the methanation system. The lay-out of the methanation section is depicted in Fig. 1. It consisted of three methanation reactors (R1, R2, R3) with a recycle from the second to the first reactor. Intermediate cooling with water knock-out was considered for removing the heat generated by the exothermic reaction. The amount of recycle was determined by an iterative process aimed at limiting the temperature rise below the recommended maximum operating temperature by the catalyst vendors in the first methanation reactor. The recycle ratio remained between 0.7 and 0.8 , and are comparable values to the ones described for the Lurgi and Haldor Topsoe's TREMP (Topsoe's Recycle Methanation Process) processes $[9,18]$. In the feed lines as well as in the product line a compressor was present to achieve the desired pressure (not depicted). The objective was to obtain directly downstream the methanation section SNG of sufficient quality for feeding in the Groningen gas grid with the following specifications: $\mathrm{CO}_{2}<3 \%, \mathrm{H}_{2}<0.5 \%, \mathrm{CO}<0.5 \%, \mathrm{H}_{2} \mathrm{O}<90 \mathrm{ppm}$ (Dew point at $-10{ }^{\circ} \mathrm{C}$ ), SNG pressure of 60 bar.

The conversion in the methanation reactors were modelled using the Gibbs minimisation. The methanation reactors' operational temperature ranges were defined based on two different types of commercial catalysts used for methanation. The maximum temperature of all 3 reactors is $650{ }^{\circ} \mathrm{C}$, inlet temperatures of methanation reactor $\mathrm{R} 1, \mathrm{R} 2$ and $\mathrm{R} 3$ were 300,250 and $220^{\circ} \mathrm{C}$ respectively. Because of the pressure difference between the feed and the final product on specification, the operating pressure of

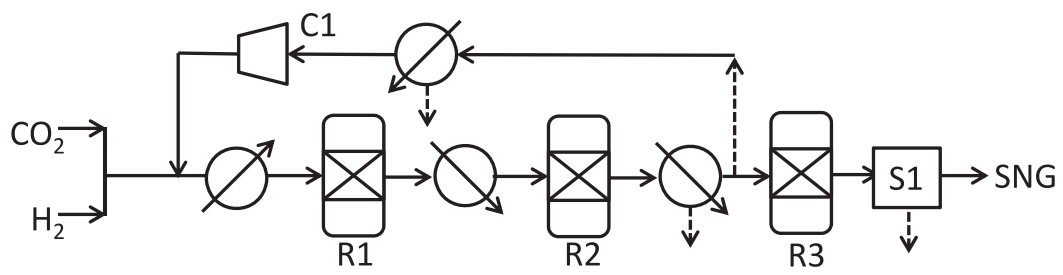

Fig. 1. Methanation process configuration with 3 reactors (R1, R2, R3) in series with recycle, intercoolers with water knock-out and drying $S 1$. 
the process has been considered as a variable in a sensitivity study up to the grid pressure of 60 bar. In the methanation process a lot of water must be removed to match the SNG specifications for grid injection. Some water may be also removed by the intermediate cooling/water knock-out stages between the methanation reactors. A compressor was used in the recycle loop and was simulated with an isentropic efficiency of 0.85 . A cooling step to $150{ }^{\circ} \mathrm{C}$ was added upstream the compressor for operation within the required temperature range. Any water that was condensed at this temperature was removed by knock-out. The final water removal S1 was first simulated as a separate glycol dehydration unit downstream the methanation for the conventional methanation case modelling.

Most of the conversion takes place in the first section of the methanation process resulting in a temperature rise in the first and second methanation reactors that approaches the limits that the catalyst may withstand. It is thus reasonable to implement a sorption enhanced process in place of the third reactor, that is used mostly to enhance the conversion such that tight product specifications may be matched. Therefore for a simple modelling of the influence of in situ water removal, the reactor R3 was considered either as a conventional reactor or as a sorption enhanced reactor. In the case of conventional reactor, R3 was modelled by a single Gibbs minimisation reactor. In contrast, when considering the sorption-enhanced methanation process case, the dehydration reaction step was combined with the reaction in which water was removed simultaneously with the reaction. The outlet of the third reactor in sorption enhanced case was assumed to be at chemical equilibrium, given that a pre-specified amount of water was taken up by the sorbent. Therefore a 3-step construct model was used to simulate the reactor R3. First a stoichiometric reactor with quantitative conversion of $\mathrm{H}_{2}$ to $\mathrm{H}_{2} \mathrm{O}$ was implemented, followed by removal of a pre-specified amount of $\mathrm{H}_{2} \mathrm{O}$, and finally a Gibbs minimisation reactor was implemented to calculate the equilibrium composition corresponding to the remaining water. The pre-defined amount of $\mathrm{H}_{2} \mathrm{O}$ removed by the sorbent was set to $99.5 \%$ of the water as present in the feed and produced by full conversion of all $\mathrm{H}_{2}$ in the feed.

A proprietary nickel based catalyst kindly supplied by CRI/Criterion Catalyst Company, Ltd. was used for the experimental study. Note that this catalyst was not specifically designed for $\mathrm{CO}_{2}$ hydrogenation. Prior to the experiments, the catalyst was pre-treated with $10 \% \mathrm{H}_{2}$ in $\mathrm{N}_{2}$ (total flow $100 \mathrm{ml} / \mathrm{min}$ ) from 25 to $250{ }^{\circ} \mathrm{C}$ during $2 \mathrm{~h}$. In the conventional methanation reaction, the catalyst bed was homogeneously diluted with alpha alumina AKP-15 (supplied by Sumitomo Chemicals) mimicking the dilution conditions of the sorption enhanced experiment (i.e. diluted by sorbent).

Both catalyst and alpha alumina (mass ratio 1:2.7) were introduced as pellets with $212-425 \mu \mathrm{m}$ diameter, to avoid excessive pressure drop and meet the conditions for plug flow regime. The experiments were performed on a fully automated test-rig designed for catalyst and sorption research purposes. The controlling system consisted of a pool of calibrated Bronkhorst mass flow controllers, including a liquid flow controller and a CEM unit for humidification of the gas stream together with two 3-way solenoid valves that were used either to direct the feed gas over the reactor or to by-pass it. Wizcon software was used to control all flows, temperatures and valve positions while programming was made to perform successive cyclic experiments. A quartz electrically heated oven was used in which a quartz reactor (ID: $10 \mathrm{~mm}$ ) was placed. Several type-K thermocouples with Eurotherm controllers were positioned in close proximity to the sorbent/catalyst bed to control and monitor the temperature of the bed. The reaction products were analysed online using two complementary detection methods: $\mathrm{CO}_{2}$ and water were analysed by IR Infrared detector (Midac FTIR I1803) while $\mathrm{CO}_{2}, \mathrm{H}_{2}, \mathrm{CH}_{4}$ and $\mathrm{N}_{2}$ concentrations were measured by gas chromatography on a Hewlett Packard M200H double channel micro-GC (Poraplot Q and molecular sieves 5A stationary phases). Before injection into the gas chromatograph, the stream was dried by a Permapure MD-series gas dryer system. For the catalytic activity test, the total feed was $150 \mathrm{ml} / \mathrm{min}$ flow, consisting of $2.5 \% \mathrm{CO}_{2}, 9.9 \% \mathrm{H}_{2}, 81.7 \% \mathrm{CH}_{4}$ and $5.9 \% \mathrm{~N}_{2}$.

For the adsorption tests zeolite $4 \mathrm{~A}$ (Merck) was tested in cyclic adsorption/desorption. Zeolite materials are indeed capable of taking very low partial pressure of steam with substantial uptake capacity at temperature of $200{ }^{\circ} \mathrm{C}$ and higher $[13,19,20]$. The adsorption experiments were carried out at 200,250 and $300{ }^{\circ} \mathrm{C}$ with a feed composition of $3.9 \% \mathrm{H}_{2} \mathrm{O}, 33.3 \% \mathrm{CH}_{4}$ and $62.8 \% \mathrm{~N}_{2}$ with a flow of $150 \mathrm{ml} / \mathrm{min}$. The sorbent was regenerated with a flow of dry nitrogen at 350,400 or $450^{\circ} \mathrm{C}$ respectively, during $1 \mathrm{~h}$. About $1 \mathrm{~g}$ of sieved material was used in these experiments.

Finally the sorption enhanced methanation reaction was tested at 250,300 and $350{ }^{\circ} \mathrm{C}$ with various regeneration temperature. The sample consisted of a mix of the Ni-based catalyst and zeolite $4 \mathrm{~A}$ of sieve fraction with a particle diameter of $212-425 \mu \mathrm{m}$. It contained 5 times more zeolite than catalyst in mass.

The same inlet flow rate (identical dry feed composition) was used for the sorption enhanced methanation experiments as well as for the conventional methanation experiments. Also, the same amount of catalyst was used. The amount of sorbent needed was chosen considering the time of sorption needed (at least $5 \mathrm{~min}$ ) considering full conversion. The regeneration was carried out at increased temperature with a flow of $150 \mathrm{ml} / \mathrm{min}$ containing $90 \%$ nitrogen and $10 \%$ hydrogen until full desorption.

\section{Results}

The current gas transport infrastructure is not designed for accommodating large amount of hydrogen next to methane and the other components of natural gas such as $\mathrm{CO}_{2}, \mathrm{~N}_{2}$ and low amounts of higher hydrocarbons. In The Netherlands for instance, the natural gas grid specifications currently allow only for very low hydrogen content (up to $0.5 \%$ ), which makes the methanation or Sabatier process a ubiquitous process to be used in biomass gasification producer gas upgrade to SNG or any process based on the $\mathrm{CO}_{2}$ methanation with renewable hydrogen. However, the thermodynamics of the exothermic Sabatier reaction favour the complete conversion of hydrogen to methane at high operating pressure and low process temperature only. Fig. 2 discloses the theoretical hydrogen concentration in the dry product stream at the outlet of the methanation section, upstream the final water removal, as a function of the operational pressure, when the 3-reactor process

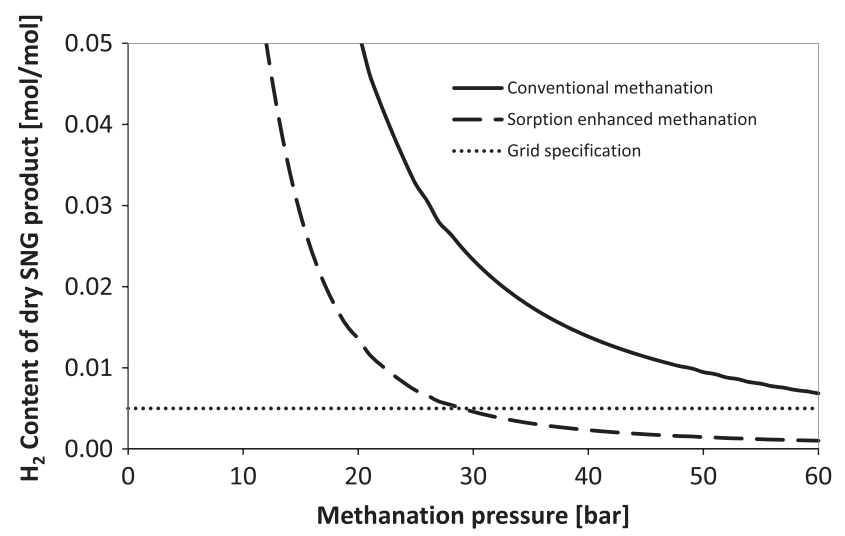

Fig. 2. $\mathrm{H}_{2}$ level in SNG produced for the conventional methanation case (3-reactor configuration) and for the sorption enhanced methanation case (sorption enhanced process in place of the 3rd reactor). The horizontal dotted line represents the maximum amount of $\mathrm{H}_{2}$ allowed in the Dutch gas grid. 
described in Fig. 1 is considered. Obviously, within the recommended operational limits of the methanation catalyst, below the pressure of the natural gas grid of 60 bar, the current gas grid $\mathrm{H}_{2}$ specification cannot be met with conventional adiabatic reactors.

For operational pressure $\leqslant 60 \mathrm{bar}$, either additional reactors or additional cleaning steps must be envisaged to match the grid specifications. In contrast, the simulation of an integrated methanation reactor with water removal in place of the 3rd conventional reactor shows that the $\mathrm{H}_{2}$ level in the SNG produced would be significantly lower and that the grid specifications for hydrogen are met at much lower operational pressure. The advantage of a sorption enhanced methanation process for the production of grid quality SNG would thus be best expressed in the lower operational pressure range, as shown by the dashed line in Fig. 2. Furthermore, additional simulations (not presented) indicate that even lower operating pressure is possible when considering more effective removal of water in the sorption enhanced reactor, when a sorbent material capable of taking up reversibly low partial pressure of water is used.

Fig. 2 also shows that for a given maximum $\mathrm{H}_{2}$ amount, the methanation section can be operated at a much lower pressure when using sorption enhanced methanation in reactor R3 in comparison with conventional methanation.

There is indeed a potential energy saving in the compression work to be supplied to the system when in place of compressing hydrogen and $\mathrm{CO}_{2}$ to high methanation operating pressure, the SNG product is compressed to the natural gas grid specification instead. This can be illustrated by a simple analytical analysis. The minimum compression energy duty with 3 three-stage compressor with intercooling were calculated using Eq. (1), that is a valid for an ideal compressible adiabatic flow (ideal gas is assumed) [21], with an isentropic efficiency of 0.85 :

$W=\frac{1}{\eta_{\text {isentropic }}} \frac{k R T}{k-1}\left[\left(\frac{p_{2}}{p_{1}}\right)^{\frac{(k-1)}{k}}+\left(\frac{p_{3}}{p_{2}}\right)^{\frac{(k-1)}{k}}+\left(\frac{p_{4}}{p_{3}}\right)^{\frac{(k-1)}{k}}-3\right]$

where

$p_{2}=\left(p_{1}^{2} p_{4}\right)^{1 / 3}$ and $p_{3}=\left(p_{4}^{2} p_{1}\right)^{1 / 3}$.

$k$ is the heat capacity ratio $\left(C_{p} / C_{v}\right)$ of single gas, $T$ is the intercooling temperature corresponding to the inlet temperature of the compressor (assumed to be $323 \mathrm{~K}$ ), $p_{1}$ and $p_{4}$ are the initial and final pressure value while $p_{2}$ and $p_{3}$ are the optimal inter-stage pressures for ideal gas, assuming that no pressure drop occurs in the intercooler. The mixture of $\mathrm{CO}_{2}$ and $\mathrm{H}_{2}$ available at 1 bar is first compressed to the methanation operational pressure and the SNG is further compressed from the methanation operational pressure to

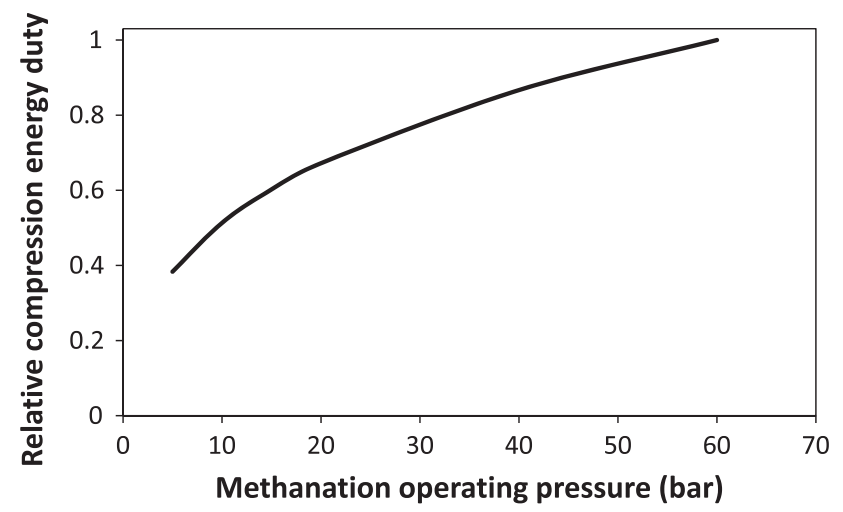

Fig. 3. Relative compression energy duty as a function of the operating pressure considering that $\mathrm{H}_{2}$ and $\mathrm{CO}_{2}$ at the inlet of the process are available at 1 bar and methane (SNG) must be compressed to 60 bar for injection in the grid. the final grid specification pressure (60 bar). The sum of the compression energy is plotted in Fig. 3 as a function of the operating pressure. Remarkably the advantages of operating the methanation at relatively low pressure may contribute to compression energy saving up to $61 \%$ at 5 bar and even more when the methanation is carried out at lower pressure. In absolute values, the compression energy duty may represents up to $10 \%$ of the energy content of the SNG product when the worst case scenario, i.e. compression of the mixture of $\mathrm{CO}_{2}$ and $\mathrm{H}_{2}$ from 1 bar to $60 \mathrm{bar}$, is considered. In addition, compression energy is supplied by electrical power that may be generated by re-electrification of SNG, which would lead to an actual thermal energy consumption of about 20\% of the SNG product, in the worst case. By operating the methanation section below 10 bar, the compression energy duty may thus be limited to less than $6 \%$, which adds a decisive argument in favour of the sorption enhanced methanation next to the combination of catalytic reaction and dehydration and the heat integration with the whole conversion chain. While $\mathrm{H}_{2}$ may be obtained by electrolysis under pressure with a good efficiency in practice, and $\mathrm{CO}_{2}$ may be supplied at moderate pressure directly from scrubbing systems (like amine absorption), the savings of compression costs still appear to be significant when the operational conditions are between 5 and 20 bar compared to operations at 60 bar.

In the sorption enhanced methanation, the sorption performance of any water sorbent is affected by the temperature rise resulting from the methanation reaction. Furthermore adsorption is an exothermic process that is favoured at low temperature and high pressure, which implies that sorbent materials for sorption enhanced methanation must have a very high affinity for water to obtain sufficient enhancement effect, even at low water partial pressure. In addition the material must be capable of taking up water in a range of relatively high temperatures corresponding to the catalytic process conditions (for instance between 200 and $400{ }^{\circ} \mathrm{C}$ ) and release it in a later regeneration step by increasing the temperature or by decreasing the water pressure. In this respect, the simulation model showed that the temperature rise in the first and second methanation reactor is quite high and lies in the $500-600{ }^{\circ} \mathrm{C}$ and $450-550^{\circ} \mathrm{C}$ ranges respectively, depending on the recycle configuration and the type of catalyst considered. It appears therefore that the most reasonable option - that does not rely on intricate and costly isothermal reactor design - is to implement a sorption enhanced step in place of the third reactor. The temperature rise in the third reactor is indeed quite limited in most cases since the amount of reactant to be converted is well below the amounts converted in the 1 st and 2 nd reactors. For instance considering two reactors in series with a recycle loop, operating at an operational pressure of 25 bar, the inlet composition of the sorption enhanced reactor that would be placed downstream the second reactor after a water condenser, would be about $2.5 \%$ $\mathrm{CO}_{2}, 10 \% \mathrm{H}_{2}, 82.5 \% \mathrm{CH}_{4}$ and $5.0 \% \mathrm{H}_{2} \mathrm{O}$. The corresponding conversion to be achieved in the sorption enhanced reactor would thus allow for a limited temperature rise. The heat released by the methanation reaction may be calculated by considering the thermodynamic equilibrium data. For example when considering an inlet reactor temperature of $200^{\circ} \mathrm{C}$, the adiabatic temperature rise would be $123^{\circ} \mathrm{C}$, with a maximum temperature of $323^{\circ} \mathrm{C}$. Down to operating pressures of $10 \mathrm{bar}$, the temperature rise in the third reactor is limited to $400{ }^{\circ} \mathrm{C}$, while below 10 bar too much of $\mathrm{CO}_{2}$ and $\mathrm{H}_{2}$ remain in the gas phase that must be converted in the third reactor, leading to excessive temperature rise to consider a sorption enhanced process. For these reasons, a mixture of $2.5 \% \mathrm{CO}_{2}$, $10 \% \mathrm{H}_{2}, 82.5 \% \mathrm{CH}_{4}$ and $5.0 \% \mathrm{H}_{2} \mathrm{O}$ was considered for an experimental proof of concept of the sorption enhanced methanation reaction with a proprietary Nickel based catalyst supplied by CRI and a zeolite sorbent. For the proof of principle it was decided to operate at atmospheric pressure since these conditions offer sufficient 
differential between equilibrium conversion and full conversion, such that the sorption enhanced effect may be unambiguously demonstrated.

At first the activity of the proprietary Nickel based catalyst supplied by CRI was tested with alpha alumina used as a diluting medium. The selected inlet gas composition was $2.4 \% \mathrm{CO}_{2}, 9.4 \% \mathrm{H}_{2}$, $77.8 \% \mathrm{CH}_{4}, 4.7 \% \mathrm{H}_{2} \mathrm{O}$ and $5.6 \% \mathrm{~N}_{2}$, nitrogen being the internal standard used for calculating the mass balance. Fig. 4 discloses both $\mathrm{H}_{2}$ and $\mathrm{CO}_{2}$ conversion level as a function of the catalytic bed temperature. With this catalyst, at a gas hourly space velocity of about $2500 \mathrm{~h}^{-1}$, the equilibrium conversion was reached between 260 and $275{ }^{\circ} \mathrm{C}$. Consistent with the thermodynamic equilibrium, the catalytic conversion at $272{ }^{\circ} \mathrm{C}$ was about $73 \pm 1 \%$ for both $\mathrm{H}_{2}$ and $\mathrm{CO}_{2}$. The corresponding methane purity may thus reach not more than $96.1 \%$ (on dry basis) and more importantly the hydrogen content of the product may not be lower than 3.1\% (on dry basis), which is still largely above the tight grid specifications mentioned earlier. Besides, the catalytic test revealed that at higher operating temperature, the consumption of methane is favoured as a result of the low operating pressures mostly and in agreement with the thermodynamics of the Sabatier reaction (see Fig. 2 and related discussion), as indicated by the negative conversion values observed above $400{ }^{\circ} \mathrm{C}$. Hence for relatively low conversion ranges that correspond to adiabatic temperature rise of up to $200^{\circ} \mathrm{C}$ and for operation at low pressures, sorption enhanced methanation has the potential of circumventing the conversion barriers encountered in conventional methanation reactors, when high methane purity and low hydrogen content are targeted.

Zeolite 4A was selected for regenerative water sorption experiments at temperature between 200 and $300^{\circ} \mathrm{C}$, at atmospheric pressure, with a nitrogen flow containing $3.9 \%$ water for the adsorption feed (Table 1). The sorbent was regenerated at temperature between 350 and $450{ }^{\circ} \mathrm{C}$, using a dry nitrogen flow at atmospheric pressure, for observing the effect of the regeneration temperature. Furthermore the influence of $\mathrm{CO}_{2}$ on adsorption capacity of water was tested in complementary experiments. Unsurprisingly, Table 1 shows that the water sorption capacity of zeolite $4 \mathrm{~A}$ decreased significantly when adsorption temperature increased from 200 to $300^{\circ} \mathrm{C}$. This confirms the earlier statement that any sorption enhanced methanation process must be considered in a system where a rather moderate temperature rise may find place. In contrast the effect of the regeneration temperature had not a large effect on the uptake capacity of the sorbent. Regeneration time and absence of water in the purge gas may have a more pronounced effect although this was not further tested in this work. Remarkably the presence of small amount of $\mathrm{CO}_{2}$ in the feed had a significant impact on the performances of the sorbent, decreasing the water sorption capacity by about $15-20 \%$, whereas the capacity for $\mathrm{CO}_{2}$ was limited to very low levels. This

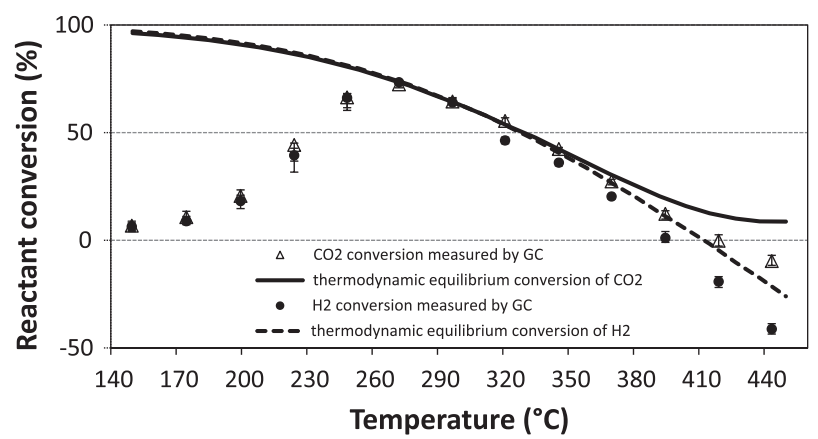

Fig. 4. $\mathrm{CO}_{2}$ and $\mathrm{H}_{2}$ conversion as a function of temperature on the proprietary Ni-based CRI methanation catalyst. Inlet composition: $2.4 \% \mathrm{CO}_{2}, 9.4 \% \mathrm{H}_{2}, 77.8 \% \mathrm{CH}_{4}$, $4.7 \% \mathrm{H}_{2} \mathrm{O}$ and $5.6 \% \mathrm{~N}_{2}$, atmospheric pressure, total flow: $150 \mathrm{ml} / \mathrm{min}$, material mass: $3.6 \mathrm{~g}$ (mass ratio alpha alumina:catalyst $=5: 1$ ). competitive adsorption between $\mathrm{CO}_{2}$ and $\mathrm{H}_{2} \mathrm{O}$ may very well be triggered by the presence of alkali cations acting as charge compensating cations, present as a consequence of incomplete ion exchange during the preparation of $\mathrm{NH}_{4}^{+}$zeolite that is the precursor of the $\mathrm{H}^{+}$-form zeolite tested in this experiment. The alkali cations are known to enhance indeed the $\mathrm{CO}_{2}$ uptake properties of zeolite by increasing their basicity [22-26]. However one may not exclude other mechanisms. Based on the water uptake performances of the zeolite $4 \mathrm{~A}$ and on the catalytic activity of the Nickel based catalyst, the experimental conditions for the demonstration of the sorption enhanced reaction were defined.

The proprietary Nickel-based catalyst and the zeolite 4A were mixed and pelletized together in a 1:5 mass ratio and were contacted with a gaseous stream comparable to a dry effluent exiting the 2 nd reactor of a methanation process. Prior to contacting the mixed catalyst and sorbent material, a pretreatment consisting of drying with a dry mixture of $10 \% \mathrm{H}_{2}$ in $\mathrm{N}_{2}$ at $400{ }^{\circ} \mathrm{C}$ for $2 \mathrm{~h}$ was applied. The reactor was then cooled down to the operating temperature and by-passed with the selected composition to ensure a good mixing of the components. Once the temperature and feeding conditions were stable, the reactor was opened and the material was exposed to the selected methanation composition. Fig. 5 discloses the transient response corresponding to the sorption enhanced methanation. Right after the start of the experiment, the methane concentration reaches $93.5 \pm 2.0 \%$ which corresponds indeed to the concentration calculated on dry basis at full conversion of $\mathrm{H}_{2}$ and $\mathrm{CO}_{2}$. The mass balance was verified with the $\mathrm{N}_{2}$ internal standard and was reconciled within the accuracy limit of the detection system. Although the analysis of concentrations between $80 \%$ and 95\% remains challenging, the methodology selected herein allowed for a relatively good accuracy as shown by the error bars in Fig. 5 . Before the breakthrough of water, a slip of $\mathrm{CO}_{2}$ preceded both breakthroughs of $\mathrm{CO}_{2}$ and $\mathrm{H}_{2}$. Water breakthrough was only detected about 2 min later in the experiment carried out at $250{ }^{\circ} \mathrm{C}$ but one may not preclude the presence of low amount of water slip that may indeed precede the main water breakthrough. Low water slip may indeed hinder the sorption enhancement effect. However the shape of the breakthrough curve of water indicates that uptake kinetics are rather slow. This maybe due to slow mass transfer between the catalytic sites and the adsorbing sites resulting into $\mathrm{CO}_{2}$ and $\mathrm{H}_{2}$ breakthrough before water breakthrough. Besides, when water breakthrough occurred, both hydrogen and $\mathrm{CO}_{2}$ reached a concentration equivalent to the concentration expected with the catalytic activity exhibited by the catalyst (Fig. 4). The sorption enhanced experiment was reproduced 10 times with a constant breakthrough time that denoted a good regenerability of the sorbent, while the sorbent uptake capacity was not ostensibly affected by the regeneration conditions. Further studies of the resistance of the catalytic material to various regeneration conditions are ongoing. Moreover it is shown that conversion is close to $100 \%$. In this work, the operating temperature was then increased to 300 and $350{ }^{\circ} \mathrm{C}$ in order to assess the performances of the materials under conditions that may be encountered in an adiabatic reactor with relatively high temperature rise.

Table 2 shows the breakthrough times for $\mathrm{H}_{2}$ and $\mathrm{H}_{2} \mathrm{O}$ at various sorption enhanced reaction temperatures, while regeneration conditions were kept at $450{ }^{\circ} \mathrm{C}$, in between the cyclic experiments. The water breakthrough time indicated that the water sorption capacity decreased when temperature increased. The corresponding breakthrough water capacities were $1.52 \mathrm{mmol} / \mathrm{g}, 1.31 \mathrm{mmol} / \mathrm{g}$ and $1.07 \mathrm{mmol} / \mathrm{g}$ at 250,300 and $350{ }^{\circ} \mathrm{C}$ respectively, when considering the total amount of water formed during the complete conversion of $\mathrm{H}_{2}$ and $\mathrm{CO}_{2}$ in addition to the amount of water produced during the period where incomplete methanation was observed, after $\mathrm{CO}_{2}$ and $\mathrm{H}_{2}$ breakthrough. These values are to be related to the sorption capacities measured by water sorption 
Table 1

$\mathrm{H}_{2} \mathrm{O}$ and $\mathrm{CO}_{2}$ adsorption capacities of zeolite $4 \mathrm{~A}$ calculated from breakthrough experiments at various temperatures, at a total pressure of 1 bar ( $\mathrm{N}_{2}$ balance).

\begin{tabular}{|c|c|c|c|c|c|}
\hline $\begin{array}{l}\text { Adsorption temperature } \\
\left({ }^{\circ} \mathrm{C}\right)\end{array}$ & $\begin{array}{l}\text { Regeneration temperature } \\
\left({ }^{\circ} \mathrm{C}\right)\end{array}$ & $\begin{array}{l}\text { Pressure of } \mathrm{H}_{2} \mathrm{O} \\
\text { (bar) }\end{array}$ & $\begin{array}{l}\text { Pressure of } \mathrm{CO}_{2} \\
\text { (bar) }\end{array}$ & $\begin{array}{l}\mathrm{H}_{2} \mathrm{O} \text { breakthrough capacity } \\
(\mathrm{mmol} / \mathrm{g})\end{array}$ & $\begin{array}{l}\mathrm{CO}_{2} \text { breakthrough capacity } \\
(\mathrm{mmol} / \mathrm{g})\end{array}$ \\
\hline 200 & 350 & 0.039 & & 1.89 & - \\
\hline 200 & 400 & 0.039 & & 2.00 & - \\
\hline 200 & 450 & 0.039 & & 1.87 & - \\
\hline 250 & 350 & 0.039 & & 1.43 & - \\
\hline 250 & 400 & 0.039 & & 1.44 & - \\
\hline 250 & 450 & 0.039 & & 1.48 & - \\
\hline 300 & 350 & 0.039 & & 1.14 & - \\
\hline 300 & 400 & 0.039 & & 1.22 & - \\
\hline 300 & 450 & 0.039 & & 1.16 & - \\
\hline 200 & 400 & 0.039 & 0.025 & 1.69 & 0.083 \\
\hline 250 & 400 & 0.039 & 0.025 & 1.23 & 0.066 \\
\hline 300 & 400 & 0.039 & 0.025 & 0.98 & 0.060 \\
\hline
\end{tabular}

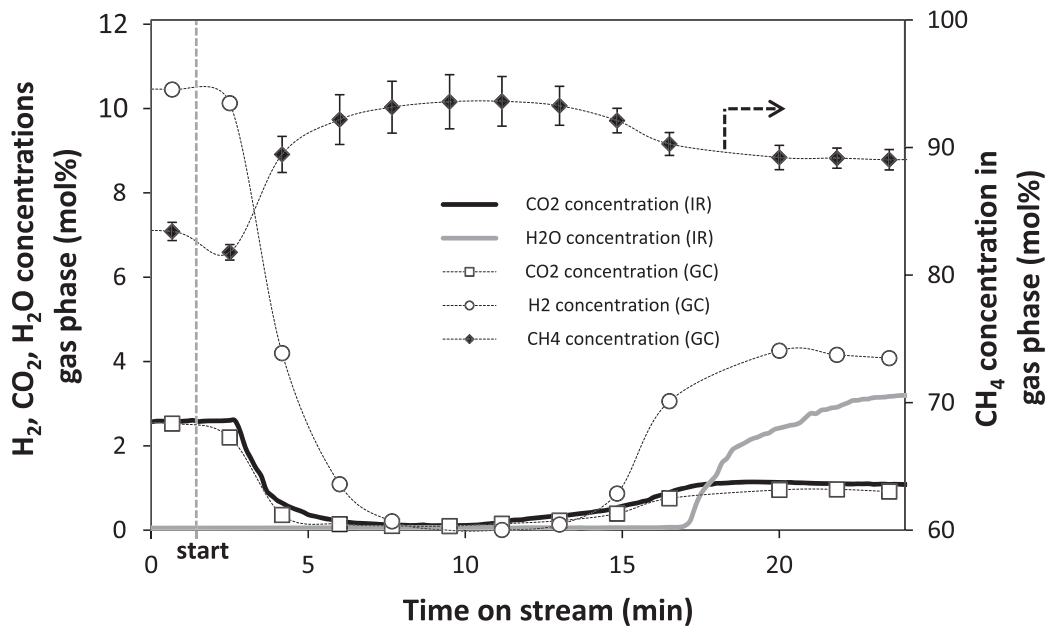

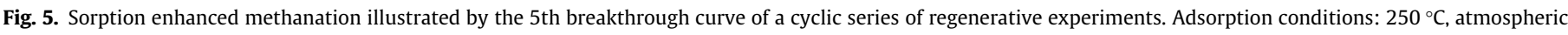

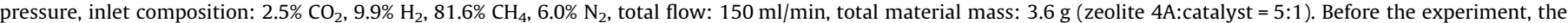

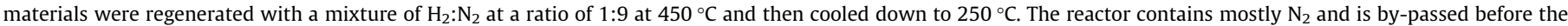

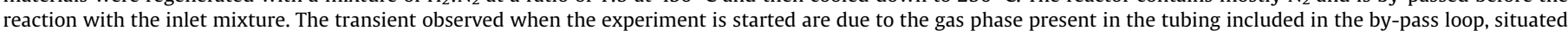
downstream the reactor and upstream the detector.

Table 2

Breakthrough time as a function of the operating temperature in the sorption enhanced methanation.

\begin{tabular}{lll}
\hline $\begin{array}{l}\text { Sorption enhanced methanation } \\
\text { operating temperature }\left({ }^{\circ} \mathrm{C}\right)\end{array}$ & $\begin{array}{l}\mathrm{H}_{2} \mathrm{O} \text { breakthrough } \\
\text { duration (min) }\end{array}$ & $\begin{array}{l}\mathrm{H}_{2} \text { breakthrough } \\
\text { duration }(\mathrm{min})\end{array}$ \\
\hline 250 & 16.3 & 12.0 \\
300 & 14.0 & 10.5 \\
350 & 11.3 & 8.8 \\
\hline
\end{tabular}

and $\mathrm{CO}_{2}$ water sorption experiments, summarized in Table 1 . The slightly higher values observed in the sorption enhanced methanation experiments may be due to the combination of slightly higher water partial pressure ( 0.05 bar at total conversion) and some water capacity of the catalytic material that counted for $1 / 6$ of the total amount of bed material in these experiments. Remarkably the breakthrough time remained quite long, even at temperature up to $350{ }^{\circ} \mathrm{C}$ which opens promising perspectives for this technology since neither the sorbent material nor the catalyst material were specifically developed for the present application.

\section{Discussion}

The thermodynamic analysis of the Sabatier process clearly showed that the conventional catalytic process necessitates multiple cascade reactors and high operational pressure to match sufficient SNG quality to allow for injection in the natural gas grid at current gas quality standards. However a number of processes for SNG production such as bio-methanation by anaerobic digestion and thermo-chemical biomass gasification may be operated at limited pressure, below 10 bars, for technical reasons. Moreover the possibility of using these processes for the production of renewable SNG by adding hydrogen generated by water electrolysis using renewable electricity calls for the development of effective and reliable methanation process that may produce grid quality SNG, while limiting the energy cost of compression of large amount of reactants. Therefore the sorption enhanced methanation process that allows for production of high grade SNG at relatively low pressure is a promising technology that allows for compression energy saving of up to $40 \%$ when methanation is operated at 10 bar instead of 60 bar, while the gaseous reactants are available at a pressure of 1 bar. When both $\mathrm{H}_{2}$ and $\mathrm{CO}_{2}$ are obtained at higher pressure, the savings of compression energy obtained by the use of sorption enhanced obviously become less dramatic, but still remain significant when both gases are supplied at $<20$ bar. For instance in the methanation of biomass gasification feed streams, in which $\mathrm{CO}_{2}$ may be converted to SNG when $\mathrm{H}_{2}$ is available from an electrolysis process, it is anticipated that the gasification product stream will be supplied at pressure $<10$ bar, when more efficient indirect gasification technology is used [27]. 
The experimental proof of principle reported herein showed that commercial materials are capable of operating in cyclic sorption enhanced conditions at the temperature range that are anticipated in the process. While breakthrough experiments exhibited already rather good capacity and catalytic activity, dedicated materials for this applications may further improve the performances of the process. For instance the development of novel efficient catalysts for Sabatier reaction $[17,28,29]$ that are specifically developed for $\mathrm{CO}_{2}$ conversion and a mixture of $\mathrm{CO} / \mathrm{CO}_{2}$ may contribute to reaching higher process performances. Similarly the specific design of dedicated sorbent material for water sorption at relevant temperature, or alternatively the staging of sorption enhanced reactors with different sorbent may greatly enhance the performances of the process by optimizing the regeneration conditions. Furthermore the experimental results also pointed clearly at the importance of improving the mass transfer rate between the catalytic sites and the adsorbent sites. This may be achieved by conceiving novel bi-functional materials such as was advocated by Borgschulte et al. [17] in their recent contribution. By tailoring both the catalytic function and the affinity for steam of the zeolitic material, by fine tuning of the microporous topology and the chemical composition of the zeolitic framework that have direct influence on the steam uptake capacity $[19,20]$, the process performances may be indeed optimized by the rational design of bi functional materials. Besides, the current results do not give a direct indication of the energy requirement of the process. Also the local temperature in the bed rise is of some concern since large local temperature rise will affect the capacity in part of the bed during the adsorption. Recently Parlikkad et al. have showed that methanation catalyst operate very efficiently in the top part of conventional bed operated at steady state causing a very sharp temperature rise on minute bed length [30]. Because the mass transfer zone associated with the steam sorption moves gradually in the adsorptive catalytic bed during the sorption enhanced methanation, the temperature rise related to highly efficient methanation catalyst may lead to dramatic effects on the transient performances of both sorbent and catalyst thereby affecting their breakthrough profiles and cyclic capacity. In contrast, it clearly appears that during desorption a higher temperature helps at removing the absorbed water. The proof of concept demonstrated in this report is indeed based on a temperature swing adsorption cycle that uses a purge gas. A proper choice of the regeneration pressure, temperature and the amount of purge gas will be therefore key parameters for optimizing the energy requirement of the process. Moreover the sorbent material selection will critically affect the operational costs since the energy requirement for the regeneration is directly related to the adsorption energy of steam on the selected material. In this respect, the optimization of the energy consumption of the process depends on the conception of a dedicated material that allows for the lowest temperature swing possible. Accordingly, the possibility to develop materials with sufficiently high capacity when used in pressure swing adsorption cycle, possibly with a purge gas, may open broader perspectives for steam enhanced reaction processes. Providing more quantitative data on the potential energy savings induced by the use of dedicated materials in the steam enhanced sorption methanation will require a more detailed experimental and modelling effort also involving possible integration with other parts of the methanation process. The experimental results on water sorption on zeolite $4 \mathrm{~A}$ are encouraging and showed that the regeneration temperature may not necessarily by much higher than the operating conditions but that the availability of a dry purge gas may be critical to keep the energy requirement low. For instance the purge gas could be the $\mathrm{H}_{2}$ produced by the electrolyser at the condition it is dried beforehand. The use of $\mathrm{CO}_{2}$ as purge gas could be an alternative at the condition that the stability of the catalyst is not affected.
Besides, when considering natural gas fields with high $\mathrm{CO}_{2}$ content that could be converted to SNG with renewable hydrogen, there may be some inert such as nitrogen or helium available for purge gas. At this point in-depth calculations for the identification of the most appropriate regeneration method appear to be relevant only when specific case are considered. The parallel development of materials and process design is thus of utmost importance for the demonstration of the performances of this process at larger scale in identified relevant cases.

\section{Conclusion}

The sorption enhanced methanation reaction process showed unique performances for high grade SNG production at low methanation pressure using commercial materials. Operating the methanation process at low pressure has been shown to enable significant energy savings for the production of SNG from a number of important processes in the production of biofuels and renewable fuels. The process showed $100 \%$ conversion of $\mathrm{H}_{2}$ to SNG, allowing for matching the specifications for injection in natural gas grid that are not designed for hydrogen transport and storage. While process energetic performance optimization may obviously benefit from the heat integration with the exothermic methanation reaction, the parallel development of dedicated bifunctional adsorbent/catalyst materials and smart process configuration is key for the translation of these advantages in a cost effective SNG upgrading method, applicable in number of processes related to renewable methane and "green gas" production.

\section{Acknowledgments}

This research has been financed by a grant of the Energy Delta Gas Research (EDGaR) program. EDGaR is co-financed by the Northern Netherlands Provinces, the European Fund for Regional Development, the Ministry of Economic Affairs and the Province of Groningen. The authors thank Arthur Fayolas from the ENSGTI (Pau, France) for his valuable contribution both to the modelling and the experimental work.

\section{References}

[1] G.A. Olah, A. Goeppert, G.K.S. Prakash, Chemical recycling of carbon dioxide to methanol and dimethyl ether: from greenhouse gas to renewable, environmentally carbon neutral fuels and synthetic hydrocarbons, J. Org. Chem. 74 (2009) 487-498.

[2] G. Centi, S. Perathoner, Opportunities and prospects in the chemical recycling of carbon dioxide to fuels, Catal. Today 148 (2009) 191-205.

[3] P. Styring, D. Jansen, H. de Coninck, H. Reith, K. Armstrong, Carbon capture and utilisation in the green economy. 501, The centre for low carbon futures, 2011.

[4] G.A. Olah, A. Goeppert, G.K.S. Prakash, Beyond Oil and Gas: The Methanol Economy, Wiley-VCH Verlag GmbH \& Co, Weinheim, 2006.

[5] F. Mohseni, M. Magnusson, M. Gorling, P. Alvfors, Biogas from renewable electricity - increasing a climate neutral fuel supply, Appl. Energy 90 (2012) $11-16$.

[6] Energy Technology Perspectives 2012, International Energy Agency, IEA Publications, Paris, France, 2012.

[7] K. Hashimoto, H. Habazaki, M. Yamasaki, S. Meguro, T. Sasaki, H. Katagiri, T. Matsui, K. Fujimura, K. Izumiya, N. Kumagai, E. Akiyama, Advanced materials for global carbon dioxide recycling, Mater. Sci. Eng. A 304-306 (2001) 88-96.

[8] P. Sabatier, J.B. Senderens, Nouvelles synthese du methane, C.R. Acad. Sci. 134 (1902) 514-516.

[9] J. Kopyscinski, T.J. Schildhauer, S.M.A. Biollaz, Production of synthetic natural gas (SNG) from coal and dry biomass : a technology review from 1950 to 2009, Fuel 89 (2010) (1950) 1763-1783.

[10] M.V. Twigg, Catalyst Handbook, second ed., Manson Publishing Ltd., London, 1996.

[11] B.T. Carvill, J.R. Hufton, M. Anand, S. Sircar, Sorption-enhanced reaction process, AIChE J. 42 (1996) 2765-2772.

[12] P.D. Cobden, P. van Beurden, H.T.J. Reijers, G.D. Elzinga, S.C.A. Kluiters, J.W. Dijkstra, D. Jansen, R.W. van den Brink, Sorption-enhanced hydrogen production for pre-combustion $\mathrm{CO}_{2}$ capture: thermodynamic analysis and experimental results, Int. J. Greenhouse Gas Control 1 (2007) 170-179.

[13] W.G. Haije, H. Geerlings, Efficient production of solar fuel using existing large scale production technologies, Environ. Sci. Technol. 45 (2011) 8609-8610. 
[14] D.P. Harrison, Sorption enhanced hydrogen production: a review, Ind. Eng. Chem. Res. 47 (2008) 6486-6501.

[15] A.F. Cunha, Y.J. Wu, J.C. Santos, A.E. Rodrigues, Sorption enhanced steam reforming of ethanol on hydrotalcite-like compounds impregnated with active copper, Chem. Eng. Res. Des. 91 (2013) 581-592.

[16] V.M. Lebarbier, R.A. Dagle, L. Kovarik, K.O. Albrecht, X. Li, L. Li, C.E. Taylor, X. Bao, Y. Wang, Sorption-enhanced synthetic natural gas (SNG) production from syngas: a novel process combining co methanation, water-gas shift, and $\mathrm{CO}_{2}$ capture, Appl. Catal. B 144 (2014) 223-232.

[17] A. Borgschulte, N. Gallandat, B. Probst, R. Suter, E. Callini, D. Ferri, Y. Arroyo, R. Erni, H. Geerlings, A. Zuttel, Sorption enhanced $\mathrm{CO}_{2}$ methanation, Phys. Chem. Chem. Phys. 15 (2013) 9620-9625.

[18] M. Sudiro, A. Bertucco, Synthetic natural gas (SNG) from coal and biomass: a survey of existing process technologies, open issues and perspectives, in: P. Potocnik (Ed.), Natural Gas, InTech, Rijeka, Croatia, 2010, pp. 105-126.

[19] B. Louis, S. Walspurger, J. Sommer, Quantitative determination of Bronsted acid sites on zeolites: a new approach towards the chemical composition of zeolites, Catal. Let. 93 (2004) 81-84.

[20] S. Walspurger, B. Louis, Insights into the structure of active sites in metaldoped solid acid catalysts, Appl. Catal. A 336 (2008) 109-115.

[21] T.F. Edgar, D.M. Himmelblau, Optimization of chemical processes, McGrawHill International Editions, Singapore, 1988.

[22] Z. Yong, V. Mata, A.E. Rodrigues, Adsorption of carbon dioxide at high temperature - a review, Sep. Purif. Technol. 26 (2002) 195-205.
[23] F. Brandani, D.M. Ruthven, The effect of water on the adsorption of $\mathrm{CO}_{2}$ and $\mathrm{C}_{3} \mathrm{H}_{8}$ on type $\mathrm{X}$ zeolites, Ind. Eng. Chem. Res. 43 (2004) 8339-8344.

[24] K.S. Walton, M.B. Abney, D.M. LeVan, $\mathrm{CO}_{2}$ adsorption in $\mathrm{Y}$ and $\mathrm{X}$ zeolites modified by alkali metal cation exchange, Microporous Mesoporous Mater. 91 (2006) 78-84.

[25] J. Shang, G. Li, R. Singh, Q. Gu, K.M. Nairn, T.J. Bastow, N. Medhekar, C.M Doherty, A.J. Hill, J.Z. Liu, P.A. Webley, Discriminative separation of gases by a molecular trapdoor mechanism in chabazite zeolites, J. Am. Chem. Soc. 134 (2012) 19246-19253.

[26] Q. Wang, J. Luo, Z. Zhong, A. Borgna, $\mathrm{CO}_{2}$ capture by solid adsorbents and their applications: current status and new trends, Energy Environ. Sci. 4 (2011) 42 55.

[27] C.M. van der Meijden, H.J. Veringa, L.P.L.M. Rabou, The production of synthetic natural gas (SNG): a comparison of three wood gasification systems for energy balance and overall efficiency, Biomass Bioenergy 34 (2010) 302-311.

[28] F. Ocampo, B. Louis, A.C. Roger, Methanation of carbon dioxide over nickelbased $\mathrm{Ce}_{0.72} \mathrm{Zr}_{0.28} \mathrm{O}_{2}$ mixed oxide catalysts prepared by sol-gel method, Appl. Catal. A 369 (2009) 90-96.

29] J. Sehested, K. Larsen, A. Kustov, A. Frey, T. Johannessen, T. Bligaard, M. Andersson, J. Norskov, C. Christensen, Discovery of technical methanation catalysts based on computational screening, Topics Catal. 45 (2007) 9-13.

[30] N.R. Parlikkad, S. Chambrey, P. Fongarland, N. Fatah, A. Khodakov, S. Capela, O. Guerrini, Modeling of fixed bed methanation reactor for syngas production: operating window and performance characteristics, Fuel 107 (2013) 254-260. 


\section{ECN}

Westerduinweg 3

P.O. Box 1

1755 LE Petten

1755 LG Petten

The Netherlands

The Netherlands

$\mathrm{T}+31885154949$

$\mathrm{F}+31885158338$

info@ecn.nl

www.ecn.nl 